\title{
Attitudinal and behavioural indices of the Second Demographic Transition: Evidence from the last three decades in Europe
}

Zuzanna Brzozowska, ORCID: 0000-0002-0235-991X

Faculty of Social Studies, Masaryk University, Czechia

Vienna University of Economics and Business, Wittgenstein Centre, Austria

\begin{abstract}
The Second Demographic Transition (SDT), which links ideational changes with demographic developments, is among the most prominent and debated theoretical frameworks in family demography. Yet, the existing attempts to operationalise it as a composite set of measures remain unevaluated. We evaluate two existing SDT indices: attitudinal and behavioural. We assess how strongly they have been linked to each other in the last three decades in Europe and test their consistency over time. Using four waves of the European Values Study and publically available demographic indicators for 23 European countries, we reconstruct, update, and evaluate the SDT indices. The attitudinal index measures postmaterialism, gender-egalitarianism, and religiosity. The behavioural index includes indicators of postponement, nonmarital childbearing, marriage, and divorce. The correlation between the attitudinal and behavioural indices is positive, but its strength varies substantially over time. The behavioural index is heavily determined by age at first marriage and at first birth, and only weakly correlated with marriage and divorce rates. The internal consistency of the attitudinal index is unstable over time. The strong link between the two SDT indices is driven by a correlation between the attitudinal index and two demographic postponement measures. As the strength of the correlation varies, conclusions based on cross-national data for a single year may be misleading. We show that the ideational and demographic changes posited by the SDT should not be treated as a package. Their operationalisation should take into account their multidimensionality. To facilitate future research, we provide ready-to-use indicator and index values used in the analysis.
\end{abstract}

Key words: Second Demographic Transition, composite measures, indices, Europe, postmaterialist values, fertility and family indicators 


\section{Introduction}

The second demographic transition (SDT) is "population researchers" to-go concept and theoretical framework for studying family and fertility changes" (Zaidi and Morgan 2017:474). Drawing on the Maslowian pyramid of human needs, it posits that the shift from materialist to postmaterialist values as identified by Inglehart $(1971,1977)$ triggers changes in family and fertility behaviour. Ideational and demographic developments are considered as packages. Postmaterialist values are associated with secularism, gender-egalitarianism and acceptance of non-traditional family forms and their diffusion gives rise to the demographic "package": rising nonmarital cohabitation and childbearing, declining fertility and marriage rates and increasing divorce rates (van de Kaa 2001). They may not occur all at once but they all take place eventually (Lesthaeghe 2010).

Importantly, it is assumed that both ideational and behavioural developments are irreversible and represent successive stages of unidirectional change. They began in Northern European countries (often called "the leaders" of the SDT), followed soon after by western parts of the continent and English-speaking non-European countries, and then by the "laggards": first in southern Europe, then in postsocialist Central-Eastern Europe, and finally also in high-income East Asian countries (Lesthaeghe 2010).

Since its formulation in 1986 (Lesthaeghe and van de Kaa 1986), the framework has been fiercely debated and its empirical underpinning has often proved to be weak (see Zaidi \& Morgan 2017, for a comprehensive overview). Surprisingly, however, its operationalisation has attracted very little scholarly attention. The proponents and opponents of the concept usually base their arguments on single ideational and demographic variables (Bystrov 2014; Coleman 
2004; Lesthaeghe 2010; Liefbroer, Merz, and Testa 2015; Treas, Lui, and Gubernskaya 2014).

Out of three attempts to operationalise the SDT as composite indices (Lesthaeghe and Neidert 2006; Sobotka 2008a, 2008b; Surkyn and Lesthaeghe 2004) only the one by Sobotka is frequently mentioned (Lesthaeghe 2010, 2020; Liefbroer, Merz, and Testa 2015; Merz and Liefbroer 2012; Miranda-Ribeiro and Garcia 2013; Zagaglia and Moretti 2014). The two indices constructed by Sobotka, attitudinal and behavioural, are based on country-level cross-sectional data for a single point in time. They have so far never been either thoroughly tested for their consistency or evaluated for more than one point in time. Consequently, we do not know whether they are indeed good indices of the SDT (i.e. whether they measure what we think they do) or whether the strong link between them reported for one point in time is random or systematic.

This paper uses data for four points in time between 1990 and 2017 for 23 European countries. Its goal is to validate the existing SDT attitudinal and behavioural indices. First, we assess their interrelationship over the last three decades in Europe. We examine how well the ideational changes captured by the ideational index explain the demographic developments. Second, we evaluate each of the two indices, i.e. we test how coherent they are and whether they equally represent each of the demographic and ideational aspects of the SDT that they include. Third, we provide ready-to-use index values as well as values of each indicator included in the indices, along with $\mathrm{R}$ code for generating them, for every analysed country and year with the aim of facilitating future research on the topic. 


\section{Data and Methods}

We use the same ideational (attitudinal) and demographic (behavioural) country-level indicators as Sobotka (2008a, 2008b). The ideational variables come from four waves of the European Values Study (EVS) conducted in years 1989-1993 (wave 1990), 1999-2001 (wave 1999), 20082010 (wave 2008) and 2017-2019 (wave 2017) (EVS 2015, 2020). The demographic indicators are retrieved from the Council of Europe, Eurostat, Human Fertility Database and national statistical agencies. Table ST1 in Supplementary Tables provides detailed information on demographic data sources for each country.

The original SDT attitudinal index, constructed for countries participating in the 1999 EVS wave, was based on respondents' answers to and opinions about eight questions and statements, as shown in Table 1, Panel A. All the items are also available in the 1990 and 2008 EVS waves, but the last 2017 wave includes only five of them (V1-5). Therefore, besides reconstructing the original eight-variable index for waves 1990-2008, we also computed its truncated version comprising the five items (V1-5) available in all waves 1990-2017. The correlation between the eight- and five-variable indices was close to one (between $92 \%$ and $94 \%$ of common variance, depending on the wave; see Fig. SG1.1 in Supplementary Graphs). This gave us a green light to use the five-variable index and thus include the 2017 wave in our study. Nevertheless, for the waves 1990-2008 we recomputed all the analyses presented in the paper using the original eight-variable index (see Fig. SG2.1-2.4 in Supplementary Graphs). There are no substantive differences in the results. 
Table 1 Indicators included in the SDT attitudinal index (Panel A) and behavioural index (Panel B)

\section{Panel A: Attitudinal variables}

\begin{tabular}{|c|c|c|c|}
\hline & Item & EVS question / statement (variable name) & Indicator included in the index \\
\hline V1 & LEISURE & $\begin{array}{l}\text { How important in your life is leisure? } \\
(\mathrm{a} 003)\end{array}$ & $\begin{array}{l}\text { Share of respondents answering } \\
\text { very important }\end{array}$ \\
\hline V2 & CONTROL & $\begin{array}{l}\text { How much freedom of choice and control } \\
\text { do you feel you have over the way your } \\
\text { life turns out? (a173) }\end{array}$ & $\begin{array}{l}\text { Mean value on the scale from } 1 \\
\text { (none at all) to } 10 \text { (a great deal) }\end{array}$ \\
\hline V3 & MARR OUT & $\begin{array}{l}\text { Marriage is an outdated institution } \\
\text { (d022) }\end{array}$ & $\begin{array}{l}\text { Share of respondents answering } \\
\text { agree }\end{array}$ \\
\hline V4 & HOME\&KIDS & $\begin{array}{l}\text { A job is alright but what most women } \\
\text { really want is a home and children } \\
\text { (d062) }\end{array}$ & $\begin{array}{l}\text { Share of respondents answering } \\
\text { strongly agree }\end{array}$ \\
\hline V5 & $\mathrm{CHURCH}$ & $\begin{array}{l}\text { How often do you attend religious } \\
\text { services? ( } \mathrm{f028} \text { ) }\end{array}$ & $\begin{array}{l}\text { Share of respondents answering } \\
\text { more than once a week or once } \\
\text { a week }\end{array}$ \\
\hline *V6 & NEED KIDS & $\begin{array}{l}\text { Do you think that a woman has to have } \\
\text { children in order to be fulfilled or is this } \\
\text { not necessary? (d019) }\end{array}$ & $\begin{array}{l}\text { Share of respondents answering } \\
\text { not necessary }\end{array}$ \\
\hline$* \mathrm{~V} 7$ & RESPECT & $\begin{array}{l}\text { One does not have the duty to respect } \\
\text { and love parents who have not earned it } \\
\text { by their behaviour and attitudes (a025) }\end{array}$ & $\begin{array}{l}\text { Share of respondents answering } \\
\text { tend to agree }\end{array}$ \\
\hline$* \mathrm{~V} 8$ & ABORTION & $\begin{array}{l}\text { Do you approve or disapprove of } \\
\text { abortion where a married couple does } \\
\text { not want to have any more children? } \\
\text { (a049) }\end{array}$ & $\begin{array}{l}\text { Share of respondents answering } \\
\text { approve }\end{array}$ \\
\hline
\end{tabular}

Panel B: Behavioural indicators (period indicators measured yearly at country-level)

\begin{tabular}{lll}
\hline \multicolumn{1}{c}{ Item } & Indicator included in the index \\
\hline I1 & MAB1 & Women's mean age at first birth \\
I2 & MAM1 & Women's mean age at first marriage \\
I3 & NONMAR & Percentage of nonmarital births \\
14 & TEEN & Sum of age-specific fertility rates below age 20, per 1,000 women \\
I5 & TFMR & Total first marriage rate for women (sum of age-specific first marriage \\
& rates) \\
I6 TDR & Total divorce rate (number of divorces per 100 marriages) \\
\hline
\end{tabular}

Note: An asterisk * denotes items available in EVS waves 1990-2008 but not in 2017. For the EVS, the country means were computed using the post-stratification (calibration) weights (gweights). The variable names given in brackets are taken from the Longitudinal Data File 1981-2008 (the variable names in the Integrated Dataset 2017 were renamed correspondingly). 
Panel B of Table 1 lists the period demographic indicators included in the SDT behavioural index. In addition to these six indicators, Sobotka adjusted the behavioural index upwards by 0.5 "if more than 10 per cent of co-residential unions were made up by cohabiting couples (data for 2001 based on Philipov 2005 and national data sources)" (Sobotka 2008b:223). Due to the lack of reliable and comparable data for the analysed countries and years, we were not able to implement this adjustment. However, the spread of cohabitation in Europe is largely reflected by the share of nonmarital births, of which the overwhelming majority are to women in coresidential unions (Brzozowska 2014; Perelli-Harris et al. 2012; Štípková 2013).

The SDT theory assumes that changes in behaviour (i.e. demographic indicators) follow ideational changes with some delay. Accordingly, the original SDT behavioural index was shifted in time with respect to the attitudinal index, i.e. it used demographic indicators measured approximately five years after the attitudinal data was collected. We were able to apply this strategy to the $1990-2008$ EVS waves but not to that of 2017 . Thus, after confirming that the correlation between the shifted and non-shifted indices was very strong (87-90\% of common variance; see Fig. SG1.2), we used the non-shifted ones to be able to include the 2017 EVS data. The Supplementary Graphs include all analyses shown in the paper repeated for the 1990-2008 EVS waves with the use of behavioural indices shifted by five years (Fig. SG3.1-3.4). Beyond that, Fig. SG1.3a-c in Supplementary Graphs show trends in all six demographic indicators measured in the EVS wave years and five years later.

Both the ideational and demographic variables are normalised, so they vary from 0 to 1 (see Equation STE1 in Supplementary Tables). In addition, the normalised demographic indicators 
TEEN and TFMR, as well as the normalised attitudinal indicators HOME\&KIDS and CHURCH were reversed before inclusion in the index, so that their high values appear as low in the index (i.e. so that they are positively related to the index and not negatively). Following Sobotka (2008a, 2008b), we computed the SDT indices as means of the normalised indicators and multiplied them by ten, so that the indices range between 0 and 10 (Equation STE2 in Supplementary Tables). Note that in order to mitigate the problem of year-on-year variations in period demographic indicators, they are computed as three-year averages. In other words, an indicator for year $y$ is in fact an average of the indicator values in years $y-1, y$ and $y+1$. If values for one or two years are missing, we use the average of values for the remaining year(s). For details on how the missing values were treated see Table ST1.

We include 23 countries that participated in at least three of the EVS waves and whose demographic indicators were available for the years of interest. The countries represent five geographic-cultural regions of Europe: North (Denmark, Finland, Iceland, Norway and Sweden), West (Austria, Belgium, France, Germany, Great Britain and the Netherlands), South (Italy, Portugal and Spain), Central-Eastern Europe or CEE (Czechia, Estonia, Hungary, Lithuania, Poland, Slovakia and Slovenia) and East (Bulgaria and Romania). We refer to the two latter regions (CEE and East) as post-socialist or post-state-socialist countries. Table ST2 in Supplementary Tables lists the exact years in which the EVS surveys were conducted in each country. 


\section{Results}

\subsection{How well do the SDT attitudes explain the SDT behaviour?}

The SDT attitudinal and behavioural indices are very closely interrelated (Pearson's $r$ close to 0.9 or $r^{2}$ equal 0.77; Figure 1 ) and show the developmental pattern predicted by the SDT: The values of both indices tend to rise with time. Figure 2 demonstrates that the relationship is not only consistent over time but also corresponds to the theoretical assumptions about the geographical divide, with Northern European countries at the ideational and demographic forefront, closely followed by Western and then Southern Europe, and with post-socialist countries closing the ranking. It is worth noticing, however, that the geographic pattern is less clear in 2017 than in previous years as the North, West and South, along with part of the CEE, have similar scores on both scales. Both indices have converged over time, with the "laggards" moving upwards faster than the "leaders". The catch-up process has been particularly fast for attitudes, with the gap between the lowest and highest values narrowing from six to four points between 1990 and 2017. However, whereas variation between the five European regions has substantially declined, the reverse is often the case within these regions. After two decades of convergence, the ideational differences between Northern countries increased in 2017. The post-socialist countries, on the other hand, have been steadily diverging in terms of their demographic behaviour: nowadays, Slovenia and Estonia score between Finland and Germany, whereas Bulgaria, Lithuania, Poland, Romania and Slovakia consistently occupy the lowest positions (with Romania being a demographic outlier in 2008 and 2017). 
Figure 1 SDT attitudinal (x-axis) and behavioural (y-axis) indices, by country and EVS wave

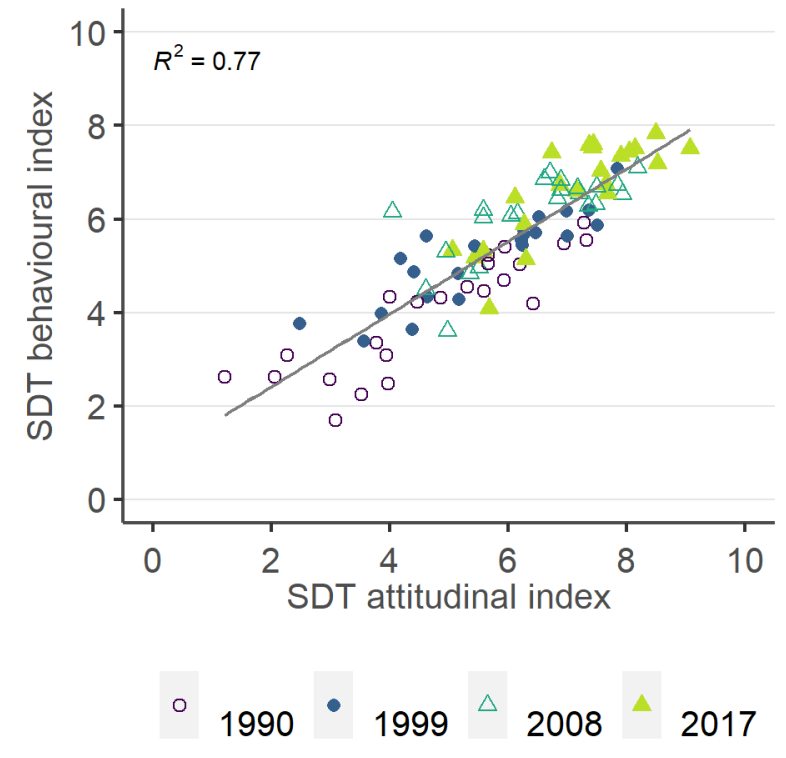

Note: Each point signifies a country's score on the attitudinal and behavioural scales. The demographic data is given for the actual year of the EVS data collection. $R^{2}$ is the square of Pearson's correlation coefficient (or the share of common variance) and the straight line represents the linear correlation of the two indices.

Figure 2 SDT attitudinal and behavioural indices, by country, region and EVS wave
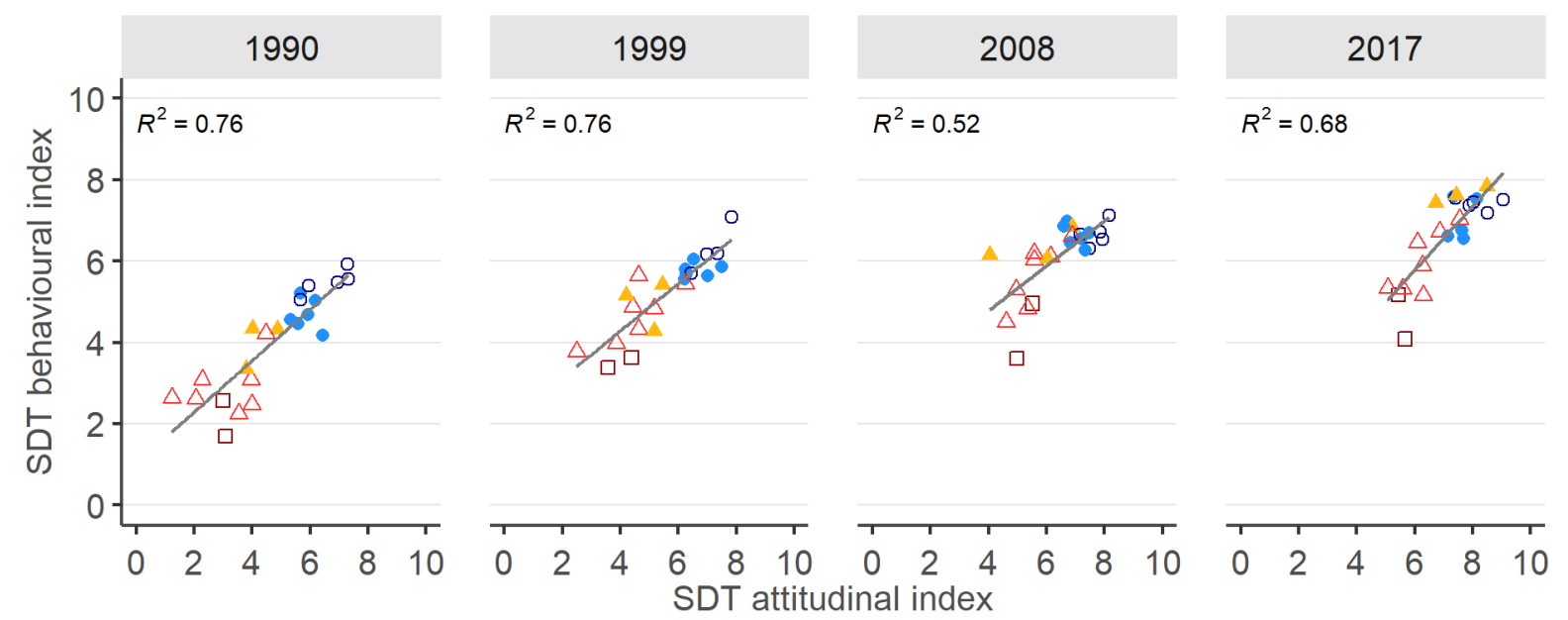

${ }^{\circ}$ North ${ }^{-}$West ${ }^{\triangle}$ South ${ }^{\triangle}$ CEE ${ }^{\square}$ East

Note: The demographic data is given for the actual year of the EVS data collection. $\mathrm{R}^{2}$ is the square of Pearson's correlation coefficient (or the share of common variance) and the straight line represents the linear correlation of the two indices. 


\subsection{How good are the SDT behavioural and attitudinal indices?}

Figure 3 shows the components of the SDT behavioural index in each analysed year and answers the question of whether all six demographic indicators are equal drivers of the observed changes. Clearly, the answer is no. The SDT behavioural index is largely driven by the "age" variables - the rising mean age at first marriage and first birth - and, to a lesser extent, by declining teenage fertility (trends for the various indicators are depicted on Fig. SG1.3ab). Their country values and their evolution largely reflect the spatial and temporal pattern assumed by the SDT, i.e. advancing in stages, consistently in one direction. In all analysed points of time, the correlation between each of these "timing" indicators (MAB1, MAM1 and TEEN) and the attitudinal index is strong, with the share of common variance ranging from $48 \%$ (TEEN) to $84 \%$ (MAM1). The corresponding figures for the share of nonmarital births are much lower but stable. The values of NONMAR tend to increase with time, as expected under the SDT framework. However, they do not entirely match the theoretical spatial pattern as some of the post-socialist countries have a persistently higher share of nonmarital births than would be expected judging from the values of other demographic variables.

The trends in the last two indicators -divorce and first marriage rates - do not at all resemble those anticipated by the theory (see Fig. SG1.3c): their levels vary greatly across countries, but not necessarily in line with the predicted spatial pattern, and in most analysed countries they fluctuate rather than following a consistent upward (TDR) or downward (TFMR) trajectory. Consequently, the relationship between each of them and the behavioural index is very unstable, varying from statistically non-significant (TDR in 1990 and 1999, TFMR in 1999) to 73\% of the common variance in 2017. In fact, excluding TDR and TFMR from the behavioural index 
would not change it much, whereas leaving out just the two "age" indicators (MAM1 and MAB1) would produce an index only loosely related (if at all) to the SDT behavioural index (see Fig. SG1.5a) and the SDT attitudinal index (Fig. SG1.5b). 
Figure 3 The SDT behavioural index (x-axis) and its components (y-axis), by country, region and EVS wave
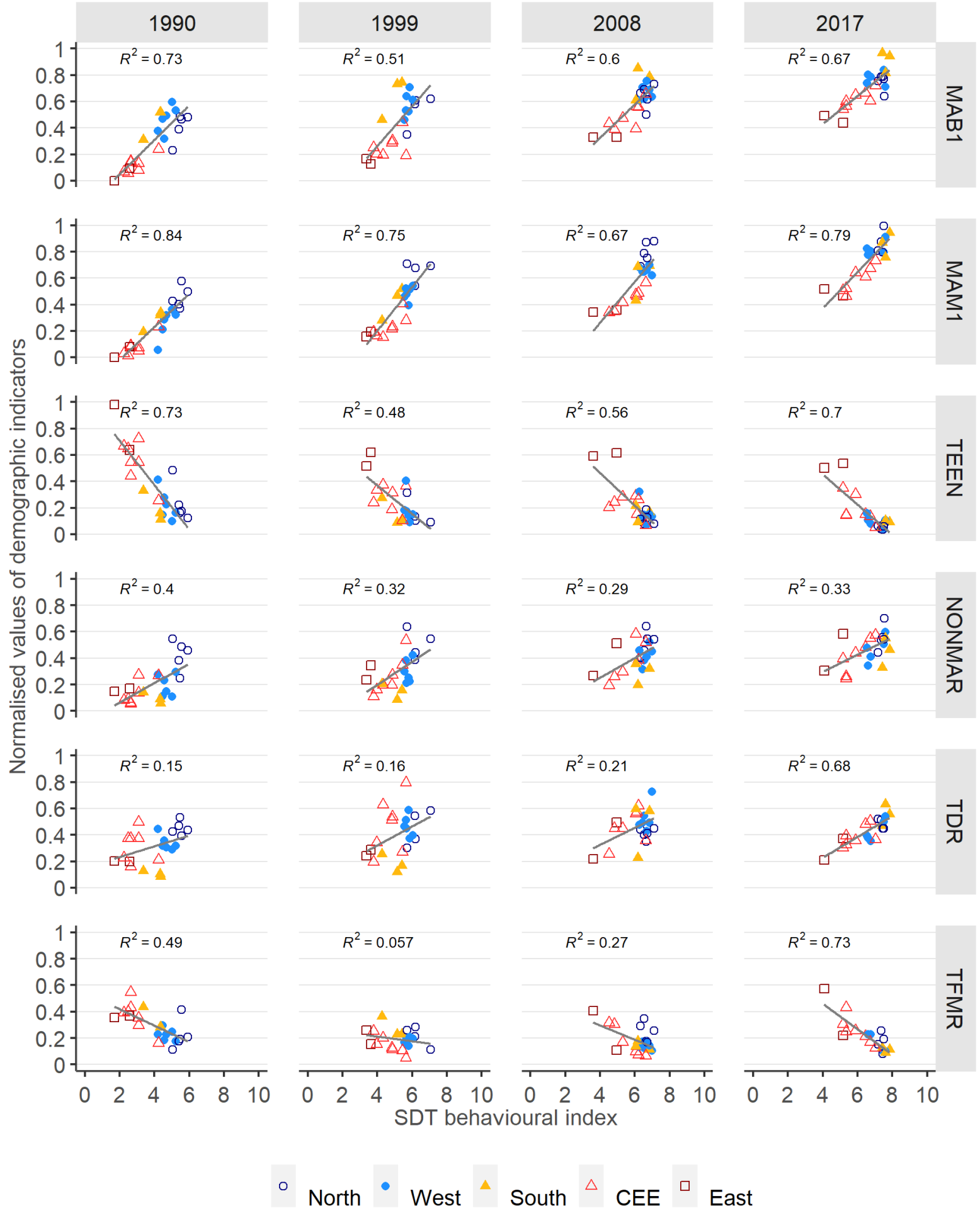

Note: The indicators TEEN and TFMR entered the index as 1-TEEN and 1-TFMR, respectively, so their increasing values correspond to increasing values of the SDT index. The demographic data is given for the actual year of the EVS data collection. $\mathrm{R}^{2}$ is the square of Pearson's correlation coefficient (or the share of common variance) and the straight line represents the linear correlation of the index and each of its components. $R^{2} s$ below 0.2 are statistically nonsignificant at the 0.05 level. 
Figure 4 The SDT attitudinal index (x-axis) and its components (y-axis), by EVS wave, country and region
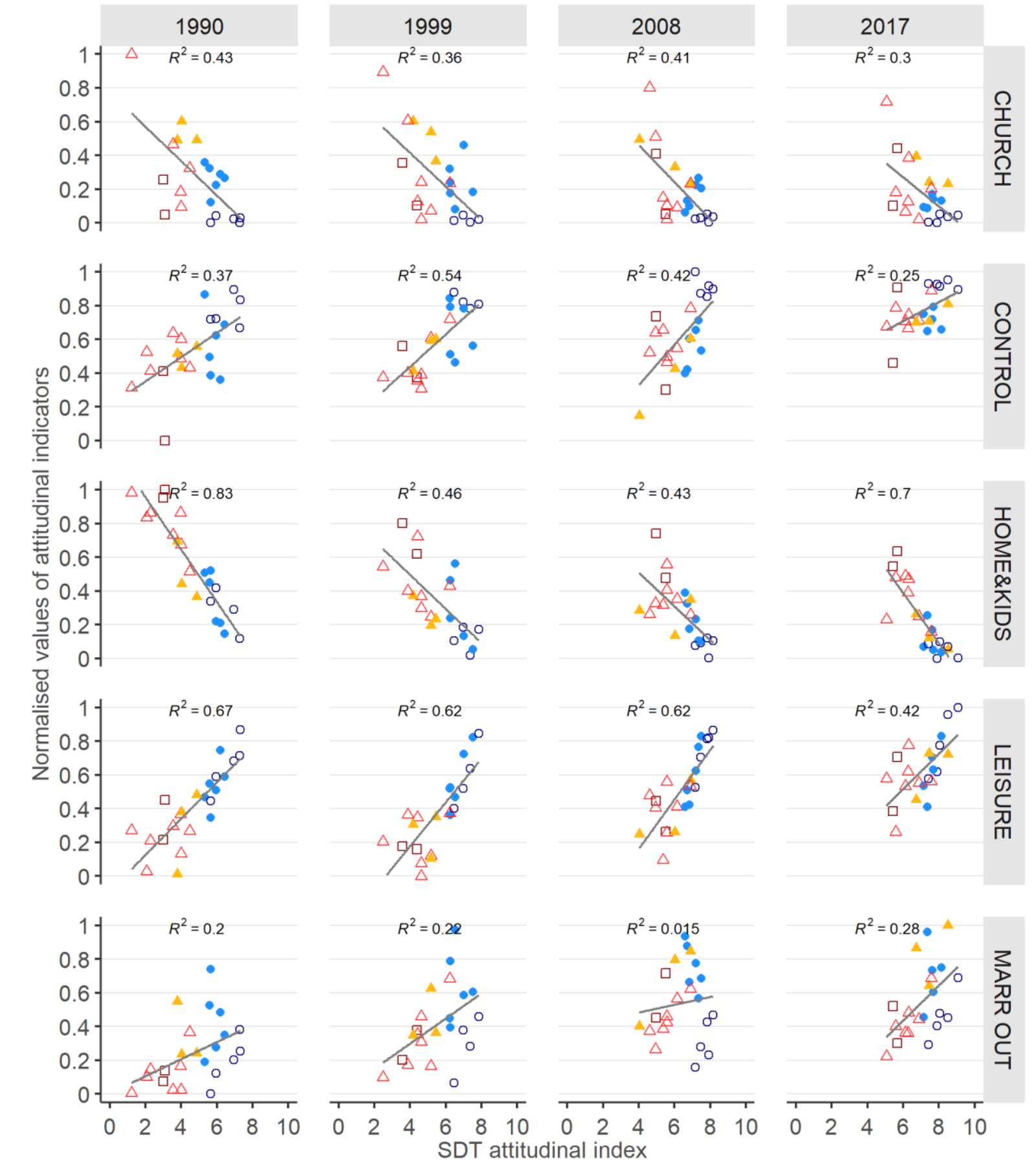

\section{${ }^{\circ}$ North ${ }^{-}$West ${ }^{\triangle}$ South ${ }^{\triangle}$ CEE ${ }^{\square}$ East}

Note: The indicators $\mathrm{CHURCH}$ and HOME\&KIDS entered the index as 1-CHURCH and 1- HOME\&KIDS, respectively, so their increasing values correspond to increasing values of the SDT index. $R^{2}$ is the square of Pearson's correlation coefficient (or the share of common variance) and the straight line represents the linear correlation of the index and each of its components. $R^{2} s$ below 0.2 are statistically non-significant at the 0.05 level. 
The indicators of the SDT attitudinal index appear to be less determining factors than those of the behavioural index (Figure 4). Overall, SDT-related attitudes vary much more than SDTrelated behaviour across time and, in particular, across countries. The two indicators most strongly correlated with the attitudinal index and which seem to best match the framework's spatial and temporal assumptions are gender attitudes (the opinion that what women really want is home and children) and the importance of leisure. The feeling of control over one's life declined in many Western- and Southern-European in 2008, possibly in response to the economic crisis, and was the weakest correlate of the index in 2017. In line with the SDT theory, most societies have become less religious with time. There are two exceptions to this trend: since 1990, church attendance has been increasing continuously in Romania and has remained constant in countries where it was already very low, e.g. Northern countries, Estonia or Czechia (see also Fig. SG1.4ab for trends in the indicators). More generally, post-socialist countries are the most heterogeneous group, with Poland being a religious outlier and Bulgaria, Czechia and Estonia belonging to the most secular countries in Europe. This weakens the correlation of church attendance with the attitudinal index.

The variable least consistent with the framework (and with the SDT attitudinal index) is the opinion that marriage is an outdated institution. At odds with other attitudinal indicators and the SDT theory, Northern societies value marriage as much as post-socialist ones do. The perception of marriage as obsolete is most widespread in the West (France, Belgium, the Netherlands and, since 2008, Austria) and, especially more recently, in the South of Europe where it has increased spectacularly, almost doubling from one wave to the next in Spain (in 
2008) and Italy (in 2017). The timing of both surges closely follows legal changes introduced in 2005 in Spain, and in 2015 in Italy, to simplify and speed up divorce procedures.

\section{Conclusions}

Our findings demonstrate that the positive correlation between the two SDT indices is largely driven by a strong link between the attitudinal index and two demographic variables measuring postponement of family transitions, namely age at first marriage and age at first birth. These two behavioural indicators, together with teenage fertility and nonmarital childbearing, largely fit the stage-like pattern of the SDT as well as the attitudinal trends which, in most cases, are practically monotonous. By contrast, the changing trends in marriage and divorce rates do not match the SDT developmental narrative and are weakly correlated with both SDT indices. This corroborates the results found by Kalmijn (2007) for Europe in the 1990s and extends them to long-term trends: whereas some SDT-related demographic behaviours are closely linked (e.g. cohabitation and marriage timing), others are not (e.g. cohabitation or marriage timing and marriage or divorce rates).

The association between both SDT indices is high overall but its strength varies greatly with time, without any clear trend. Thus, care is needed when drawing conclusions based on crossnational data for a single year. The correlation of the attitudinal index with its single components varies in a similarly erratic manner from one point in time to the next, signalling consistency problems. This finding supports previous microlevel research concluding that the internal consistency of the index is very low (Lakomý 2019), and is in line with a study showing substantial variation in correlates of different fertility-related norms (Liefbroer, Merz, and Testa 2015). Clearly, the ideational and demographic changes posited by the SDT should not be 
treated as a package. The weaknesses of the two indices evaluated in this paper illustrate the

problem acknowledged by one of the founding fathers of the SDT: it is problematic to force "a multi-dimensional reality into a linear, sequential narrative" (van de Kaa 1994:104; cited after

Zaidi and Morgan 2017). Our findings invite future research to look for an operationalisation of the concept that reflects the "multidimensional reality" of SDT-related developments.

\section{Acknowledgments}

This research was conducted as part of the Project MSCAfellow2@MUNI

(CZ.02.2.69/0.0/0.0/18_070/0009846) financed by the Operational Programme Research, Development and Education. I am grateful to Tomáš Sobotka who has critically read and commented on the text.

\section{References}

Brzozowska, Z. (2014). Births to single mothers: Age- and education-related changes in Poland between 1985 and 2010. Demographic Research 30:1445-1462. doi:10.4054/DemRes.2014.30.52.

Bystrov, E. (2014). Testing the Second Demographic Transition Theory with Seemingly Unrelated Regression: Marital Postponement and Human Empowerment. European Sociological Review 30(4):483-499. doi:10.1093/esr/jcu054.

Coleman, D.A. (2004). Why we don't have to believe without doubting in the 'Second Demographic Transition' -some agnostic comments. Vienna Yearbook of Population Research:11-24.

EVS (2015). European Values Study Longitudinal Data File 1981-2008 (EVS 1981-2008). Cologne: GESIS Data Archive, Cologne. ZA4804 Data file Version 3.0.0. https://doi.org/10.4232/1.13486.

EVS (2020). European Values Study 2017: Integrated Dataset (EVS 2017). Cologne: GESIS Data Archive, Cologne. ZA7500 Data file Version 4.0.0. https://doi.org/10.4232/1.13560.

Inglehart, R. (1971). The Silent Revolution in Europe: Intergenerational Change in Post-Industrial Societies. The American Political Science Review 65(4):991-1017. doi:10.2307/1953494.

Inglehart, R. (1977). The Silent Revolution: Changing Values and Political Styles among Western Publics. Princeton University Press.

van de Kaa, D.J. (1994). The second demographic transition revisited: Theories and expectations. In: Beets, G., van den Brinkel, J., Cliquet, R. and Dooghe, G. (eds.). Population and Family in the Low Countries 1993: Late Fertility and Other Current Issues. Berwyn/Amsterdam: Swets and Zeitlinger: 81-126.

van de Kaa, D.J. (2001). Postmodern Fertility Preferences: From Changing Value Orientation to New Behavior. Population and Development Review 27:290-331. 
Kalmijn, M. (2007). Explaining cross-national differences in marriage, cohabitation, and divorce in Europe, 1990-2000. Population studies 61(3):243-63. doi:10.1080/00324720701571806.

Lakomý, M. (2019). The role of values and of socioeconomic status in the education-fertility link among men and women. In: Vienna Yearbook of Population Research 2017. Vienna: Austrian Academy of Sciences Press. https://www.austriaca.at/0xc1aa5576\%200x003905f3.pdf.

Lesthaeghe, R. (2010). The Unfolding Story of the Second Demographic Transition. Population and Development Review 36(2):211-251. doi:10.1111/j.1728-4457.2010.00328.x.

Lesthaeghe, R. (2020). The second demographic transition, 1986-2020: sub-replacement fertility and rising cohabitation-a global update. Genus 76(1):10. doi:10.1186/s41118-020-00077-4.

Lesthaeghe, R. and van de Kaa, D.J. (1986). Twee demografische transities? In: Lesthaeghe, R. and van de Kaa, D. J. (eds.). Bevolking: groei of krimp (Boekafl. Mens en Maatschappij). Deventer: Van Loghum-Slaterus: 9-24. http://www.shclimburg.nl/twee-demografische-transities.

Lesthaeghe, R. and Neidert, L. (2006). The Second Demographic Transition in the United States: Exception or Textbook Example? Population and Development Review 32(4):669-698. doi:10.1111/j.1728-4457.2006.00146.x.

Liefbroer, A.C., Merz, E.-M., and Testa, M.R. (2015). Fertility-Related Norms Across Europe: A Multi-level Analysis. In: Philipov, D., Liefbroer, A. C. and Klobas, J. (eds.). Reproductive Decision-Making in a Macro-Micro Perspective. Springer Netherlands. //www.springer.com/us/book/9789401794008.

Merz, E.-M. and Liefbroer, A.C. (2012). The Attitude Toward Voluntary Childlessness in Europe: Cultural and Institutional Explanations. Journal of Marriage and Family 74(3):587-600. doi:10.1111/j.1741-3737.2012.00972.x.

Miranda-Ribeiro, A. and Garcia, R. (2013). Transition or transitions? Analyzing the fertility decline in Brazil in the light of educational levels. Revista Latinoamericana de Población. doi:10.31406/RELAP2013.V7.12.N13.4.

Perelli-Harris, B., Kreyenfeld, M., Sigle-Rushton, W., Keizer, R., Lappegård, T., Jasilioniene, A., Berghammer, C., and Di Giulio, P. (2012). Changes in union status during the transition to parenthood in eleven European countries, 1970s to early 2000s. Population studies 66(2):167182. doi:10.1080/00324728.2012.673004.

Sobotka, T. (2008a). Does Persistent Low Fertility Threaten the Future of European Populations. In: Surkyn, J., Deboosere, P. and Van Bavel, J. (eds.). Demographic Challenges for the 21st Century: A State of the Art in Demography. Brussels: VUB Press Brussels University Press: 27-90.

Sobotka, T. (2008b). Overview Chapter 6: The diverse faces of the Second Demographic Transition in Europe. Demographic Research 19:171-224. doi:10.4054/DemRes.2008.19.8.

Štípková, M. (2013). Declining health disadvantage of non-marital children: Explanation of the trend in the Czech Republic 1990-2010. Demographic Research 29:663-706. doi:10.4054/DemRes.2013.29.25.

Surkyn, J. and Lesthaeghe, R. (2004). Value Orientations and the Second Demographic Transition (SDT) in Northern, Western and Southern Europe: An Update. Demographic Research Special 3:45-86. doi:10.4054/DemRes.2004.S3.3.

Treas, J., Lui, J., and Gubernskaya, Z. (2014). Attitudes on marriage and new relationships: Cross-national evidence on the deinstitutionalization of marriage. Demographic Research 30(54):1495-1526. doi:10.4054/DemRes.2014.30.54.

Zagaglia, B. and Moretti, E. (2014). Fertility Dynamics in Europe: Reflections on the Principal Interpretative Paradigms in Light of Some Empirical Evidence. Rivista Italiana di Economia Demografia e Statistica LXVIII(3/4). https://pdfs.semanticscholar.org/77df/6a5ee6e1005a72850b8121bf5a9c644d4537.pdf.

Zaidi, B. and Morgan, S.P. (2017). The Second Demographic Transition Theory: A Review and Appraisal. Annual Review of Sociology 43(1):473-492. doi:10.1146/annurev-soc-060116-053442. 